\title{
Assessment of Human Exposure to Five Alternaria Mycotoxins in China by Biomonitoring Approach
}

\author{
Kai Fan ${ }^{1}$, Wenbo Guo ${ }^{1}$, Qingwen Huang ${ }^{1}$, Jiajia Meng ${ }^{1}$, Qi Yao ${ }^{2}$, Dongxia Nie ${ }^{1}$, Zheng Han ${ }^{1}$ \\ and Zhihui Zhao ${ }^{1, *}$ \\ 1 Key Laboratory of Protected Horticultural Technology, Institute for Agro-Food Standards and Testing \\ Technology, Academy of Agricultural Sciences, Shanghai 201403, China; fankai@saas.sh.cn (K.F.); \\ guo1103bo@126.com (W.G.); huangqingwen@saas.sh.cn (Q.H.); mengjiajia@saas.sh.cn (J.M.); \\ niedongxia@saas.sh.cn (D.N.); hanzheng@saas.sh.cn (Z.H.) \\ 2 Department of Pathology and Pathophysiology, School of Medicine and Life Sciences, \\ Nanjing University of Traditional Chinese Medicine, Nanjing 210023, China; qiqiyao@126.com \\ * Correspondence: zhaozhihui@saas.sh.cn; Tel.: +86-21-62202875
}

Citation: Fan, K.; Guo, W.; Huang, Q.; Meng, J.; Yao, Q.; Nie, D.; Han, Z.; Zhao, Z. Assessment of Human Exposure to Five Alternaria Mycotoxins in China by Biomonitoring Approach. Toxins 2021, 13, 762. https://doi.org/ $10.3390 /$ toxins 13110762

Received: 10 September 2021

Accepted: 26 October 2021

Published: 28 October 2021

Publisher's Note: MDPI stays neutral with regard to jurisdictional claims in published maps and institutional affiliations.

Copyright: (c) 2021 by the authors. Licensee MDPI, Basel, Switzerland. This article is an open access article distributed under the terms and conditions of the Creative Commons Attribution (CC BY) license (https:/ / creativecommons.org/licenses/by/ $4.0 /)$.

\begin{abstract}
This biomonitoring study was conducted to investigate the concentration levels of five Alternaria mycotoxins in urine samples from 269 healthy volunteers living in the Yangtze River Delta, China. Alternariol (AOH), alternariol monomethyl ether (AME), tenuazonic acid (TeA) and tentoxin (TEN) were detected in $38.3 \%, 48.7 \%, 63.9 \%$ and $23.4 \%$ of urine samples with the concentrations ranging from 0.057 to $45.8 \mathrm{ng} / \mathrm{mL}, 0.020$ to $0.802 \mathrm{ng} / \mathrm{mL}, 0.050$ to $80.6 \mathrm{ng} / \mathrm{mL}$ and 0.021 to $0.939 \mathrm{ng} / \mathrm{mL}$, respectively. Altenuene (ALT) was not detected in any urine sample. Based on the urinary concentrations, the probable daily intake (PDI) values of Alternaria mycotoxins were calculated, and $100 \%, 99.2-100 \%, 0.372 \%$ and $1.12 \%$ of participants exceeded the threshold of toxicological concern (TTC) values for $\mathrm{AOH}, \mathrm{AME}, \mathrm{TeA}$ and TEN, respectively. This study revealed high potential health risks related to the contaminations of major Alternaria mycotoxins in China and highlighted the necessity for more toxicological studies to provide better basis for further comprehensive risk assessments.
\end{abstract}

Keywords: Alternaria mycotoxin; human urine; UPLC-MS/MS; risk assessment

Key Contribution: This biomonitoring study was performed to evaluate the health risks related to the contamination of the major Alternaria mycotoxins in the Chinese population; for the first time.

\section{Introduction}

Alternaria mycotoxins are secondary metabolites produced by Alternaria species, which have been identified as ubiquitously pathogenic genus causing considerable economic losses in worldwide agriculture [1]. Among more than 70 Alternaria toxins characterized, alternariol $(\mathrm{AOH})$, alternariol monomethyl ether (AME), altenuene (ALT), tenuazonic acid (TeA), and tentoxin (TEN) are the most important members (Figure S1) [2,3]. The European Food Safety Authority (EFSA) has evaluated Alternaria toxins as potentially causing risks to human health and established the threshold of toxicological concern (TTC) values as $2.5 \mathrm{ng} / \mathrm{kg}$ bw/day for $\mathrm{AOH}$ and $\mathrm{AME}$, and $1500 \mathrm{ng} / \mathrm{kg}$ bw/day for TeA and TEN, respectively $[4,5]$.

Due to the strong environmental adaptability, especially growth and production of toxic secondary metabolites at low temperatures, Alternaria species may contaminate all stages of the food chain, and Alternaria mycotoxins have been frequently detected in numerous food items, including cereals, fruits, dried fruits, vegetables, juices and wine [3,6-9]. As a consequence, through environments and ingestions of contaminated foods, humans are easily exposed to Alternaria mycotoxins. The risks related to the mycotoxins exposure can be estimated based on occurrence data in foods combined with consumption 
data (external exposure), or, alternatively, via human mycotoxin biomarkers in biological samples (e.g., blood, urine, or breast milk) (biomonitoring) [10,11]. Considering the heterogeneous distribution of mycotoxins in food, the probable insufficient representation of consumption data, and the existence of multiple contamination sources, biomonitoring is recognized as a more effective and valuable approach [12-14], and has been successfully conducted to evaluate human exposure to different mycotoxins in Africa, Europe, Asia, and America [15-19]. With regard to Alternaria toxins, despite several external exposure assessments $[3,5,20-23]$, there were only limited reports on the biomonitoring approach Asam et al., [24] and Hövelmann et al., [25] reported the detection of TeA in German individuals, while $\mathrm{AOH}$ was identified in urine samples from Portugal [26]. In China, such biomonitoring data are scarce so far, except for a recent methodological study, in which, an ultrahigh-performance-liquid chromatography tandem mass spectrometry (UPLC-MS/MS) method was developed and preliminarily applied, indicating the presence of Alternaria mycotoxins in urine samples [27]. However, the dietary intakes and health risks related to the major Alternaria toxins are still in need of investigation.

Therefore, the purpose of the current research was to investigate the occurrence of five important Alternaria mycotoxins (AOH, AME, ALT, TeA and TEN) in 269 first morning urine samples from healthy volunteers living in the Yangtze River Delta, China. Therefore, for the first time, the probable daily intake (PDI) values for multiple Alternaria mycotoxins were preliminarily estimated and compared with the respective TTC values to characterize the associated health risks.

\section{Results and Discussion}

\subsection{Method Validation}

The performance parameters of the analytical method for the determination of five Alternaria mycotoxins in urine were summered in Table 1 . The signal suppression/enhancements (SSEs) for $\mathrm{AOH}, \mathrm{AME}$ and TeA were $54.4 \%, 70.0 \%$ and $58.7 \%$, respectively, verifying significant matrix effects. Thus, matrix-matched calibration curves were established as an alternative accurate quantitation strategy for the lack of the isotope-labelling standards [28]. As urine composition may vary among individuals, it should bear in mind that the uncertainties related to the calculations of the concentrations of Alternaria mycotoxins might be relatively higher. Good linear responses for all analytes have been obtained with the coefficients of determination $\left(\mathrm{R}^{2}\right)$ between 0.994 and 0.999 (Table S1). The limit of detection (LOD) and limit of quantification (LOQ) values for individual Alternaria mycotoxins ranged from 0.02 to $0.2 \mathrm{ng} / \mathrm{mL}$ and 0.05 to $0.5 \mathrm{ng} / \mathrm{mL}$, respectively. The recovery values for Alternaria mycotoxins ranged from $75 \%$ to $104 \%$, and the maximum intra-day precision and inter-day precision were $9.9 \%$ and $11.8 \%$, respectively. Thus, the analytical method was considered as adequate for the analysis of the Alternaria mycotoxins in urine.

\subsection{Levels of Alternaria Mycotoxins in Urine Samples}

In total, the analysis of first-morning urine samples from 269 participants revealed the presence of four Alternaria mycotoxins (AOH, AME, TeA and TEN) in $87.0 \%$ of the samples (Table 2). ALT was not detected in any urine sample. TeA was the most frequent Alternaria mycotoxin found in urine, with $63.9 \%$ of positive samples at levels ranging from 0.050 to $80.6 \mathrm{ng} / \mathrm{mL}$ (0.019 to $63.8 \mathrm{ng} / \mathrm{mg}$ creatinine $(\mathrm{Cr}))$, with a mean value of $2.08 \pm 7.52 \mathrm{ng} / \mathrm{mL}(1.82 \pm 6.29 \mathrm{ng} / \mathrm{mg} \mathrm{Cr})$. AME was the second most frequently detected Alternaria mycotoxin (48.7\%) at concentrations ranging from 0.020 to $0.802 \mathrm{ng} / \mathrm{mL}$ ( 0.010 to $2.12 \mathrm{ng} / \mathrm{mg} \mathrm{Cr}$ ). AOH and TEN were detected in $38.3 \%$ and $23.4 \%$ of samples, with the mean values of $1.49 \pm 5.05 \mathrm{ng} / \mathrm{mL}(1.59 \pm 5.50 \mathrm{ng} / \mathrm{mg} \mathrm{Cr})$ and $0.041 \pm 0.105 \mathrm{ng} / \mathrm{mL}$ $(0.056 \pm 0.231 \mathrm{ng} / \mathrm{mg} \mathrm{Cr})$, respectively. 
Table 1. Method validations for the five Alternaria mycotoxins in urine samples.

\begin{tabular}{|c|c|c|c|c|c|c|c|}
\hline Mycotoxins & $\begin{array}{c}\text { LOD } \\
(\mathrm{ng} / \mathrm{mL})\end{array}$ & $\begin{array}{c}\text { LOQ } \\
(\mathrm{ng} / \mathrm{mL})\end{array}$ & $\begin{array}{l}\text { SSE } \\
(\%)\end{array}$ & $\begin{array}{l}\text { Spiked Levels } \\
\text { (ng/mL) }\end{array}$ & $\begin{array}{c}\text { Recovery } \\
(\%)\end{array}$ & $\begin{array}{c}\text { Intra-Day } \\
\text { Precision (\%) }\end{array}$ & $\begin{array}{c}\text { Inter-Day } \\
\text { Precision (\%) }\end{array}$ \\
\hline \multirow{3}{*}{$\mathrm{AOH}$} & \multirow{3}{*}{0.04} & \multirow{3}{*}{0.1} & \multirow{3}{*}{54.4} & 0.1 & 93 & 2.4 & 10.7 \\
\hline & & & & 0.5 & 85 & 5.8 & 5.4 \\
\hline & & & & 5 & 91 & 2.1 & 5.2 \\
\hline \multirow{3}{*}{ AME } & \multirow{3}{*}{0.02} & \multirow{3}{*}{0.05} & \multirow{3}{*}{70.0} & 0.05 & 75 & 6.7 & 8.0 \\
\hline & & & & 0.2 & 93 & 3.4 & 2.3 \\
\hline & & & & 2 & 92 & 6.2 & 1.8 \\
\hline \multirow{3}{*}{ ALT } & \multirow{3}{*}{0.2} & \multirow{3}{*}{0.5} & \multirow{3}{*}{88.7} & 0.5 & 104 & 5.9 & 10.8 \\
\hline & & & & 2 & 101 & 3.5 & 4.3 \\
\hline & & & & 10 & 100 & 9.9 & 4.6 \\
\hline \multirow{3}{*}{$\mathrm{TeA}$} & \multirow{3}{*}{0.05} & \multirow{3}{*}{0.1} & \multirow{3}{*}{58.7} & 0.1 & 77 & 7.6 & 11.8 \\
\hline & & & & 0.5 & 90 & 6.7 & 7.7 \\
\hline & & & & 5 & 97 & 9.6 & 11.7 \\
\hline \multirow{3}{*}{ TEN } & \multirow{3}{*}{0.02} & \multirow{3}{*}{0.05} & \multirow{3}{*}{84.1} & 0.05 & 90 & 9.5 & 8.6 \\
\hline & & & & 0.2 & 90 & 2.6 & 3.3 \\
\hline & & & & 2 & 101 & 2.3 & 3.3 \\
\hline
\end{tabular}

$\mathrm{AOH}=$ alternariol; $\mathrm{AME}=$ alternariol monomethyl ether; ALT = altenuene; TeA = tenuazonic acid; TEN = tentoxin; LOD = limit of detection, determined at signal-to-noise ratio $(S / N)=3 ; \mathrm{LOQ}=$ limit of quantification, determined at $\mathrm{S} / \mathrm{N}=10 ; \mathrm{SSE}=$ signal suppression/enhancement, calculated by comparing the slope of the matrix-matched calibration curve with that of the standard calibration curve; recovery, intra- and inter-day precision, performed in five replicates using blank urine samples spiked with low, intermediate and high concentration levels.

Table 2. Occurrence of $\mathrm{AOH}, \mathrm{AME}, \mathrm{TeA}$ and TEN in urine samples in the Yangtze River Delta, China.

\begin{tabular}{|c|c|c|c|c|c|}
\hline Mycotoxins & All $(n=269)$ & Shanghai $(n=93)$ & Nanjing $(n=86)$ & Hangzhou $(n=90)$ & $p$-Value ${ }^{a}$ \\
\hline \multicolumn{6}{|l|}{$\mathrm{AOH}$} \\
\hline Frequency \% (n) & $38.3(103)$ & $36.6(34)$ & $30.2(26)$ & $47.8(43)$ & \\
\hline Mean $\pm \mathrm{SD}(\mathrm{ng} / \mathrm{mL})$ & $1.49 \pm 5.05$ & $0.760 \pm 2.80$ & $0.235 \pm 0.476$ & $3.46 \pm 7.90$ & 0.001 \\
\hline Range $(\mathrm{ng} / \mathrm{mL})$ & $0.057-45.8$ & $0.061-25.0$ & $0.057-3.02$ & $0.088-45.8$ & \\
\hline Mean \pm SD (ng/mg Cr $)$ & $1.59 \pm 5.50$ & $0.855 \pm 4.46$ & $0.270 \pm 0.554$ & $3.61 \pm 7.98$ & 0.004 \\
\hline Range (ng/mg Cr) & $0.037-43.9$ & $0.084-42.6$ & $0.044-3.13$ & $0.037-43.9$ & \\
\hline \multicolumn{6}{|l|}{ AME } \\
\hline Frequency \% (n) & $48.7(131)$ & $53.8(50)$ & $51.2(44)$ & $41.1(37)$ & \\
\hline Mean $\pm \mathrm{SD}(\mathrm{ng} / \mathrm{mL})$ & $0.102 \pm 0.120$ & $0.113 \pm 0.131$ & $0.111 \pm 0.113$ & $0.082 \pm 0.113$ & 0.140 \\
\hline Range (ng/mL) & $0.020-0.802$ & $0.027-0.802$ & $0.020-0.171$ & $0.020-0.640$ & \\
\hline Mean \pm SD (ng/mg Cr $)$ & $0.111 \pm 0.188$ & $0.101 \pm 0.125$ & $0.115 \pm 0.142$ & $0.117 \pm 0.267$ & 0.116 \\
\hline Range (ng/mg Cr) & $0.010-2.12$ & $0.010-0.406$ & $0.011-0.193$ & 0.010-2.12 & \\
\hline \multicolumn{6}{|l|}{ TeA } \\
\hline Frequency \% (n) & $63.9(172)$ & $75.3(70)$ & $74.4(64)$ & $42.2(38)$ & \\
\hline Mean $\pm \mathrm{SD}(\mathrm{ng} / \mathrm{mL})$ & $2.08 \pm 7.52$ & $2.94 \pm 8.32$ & $1.68 \pm 4.49$ & $1.57 \pm 8.85$ & 0.000 \\
\hline Range (ng/mL) & $0.050-80.55$ & $0.052-47.5$ & $0.05-33.4$ & $0.052-80.6$ & \\
\hline Mean \pm SD $(\mathrm{ng} / \mathrm{mg} \mathrm{Cr})$ & $1.82 \pm 6.29$ & $2.41 \pm 7.82$ & $2.00 \pm 4.95$ & $1.06 \pm 5.60$ & 0.001 \\
\hline Range (ng/mg Cr) & $0.019-63.8$ & $0.019-63.8$ & $0.032-29.0$ & $0.093-50.4$ & \\
\hline \multicolumn{6}{|l|}{ TEN } \\
\hline Frequency \% (n) & $23.4(63)$ & $20.4(19)$ & $11.6(10)$ & $37.8(34)$ & \\
\hline Mean $\pm \mathrm{SD}(\mathrm{ng} / \mathrm{mL})$ & $0.041 \pm 0.105$ & $0.026 \pm 0.041$ & $0.018 \pm 0.031$ & $0.079 \pm 0.169$ & 0.000 \\
\hline Range $(\mathrm{ng} / \mathrm{mL})$ & $0.021-0.939$ & $0.021-0.226$ & $0.026-0.239$ & $0.025-0.939$ & \\
\hline Mean \pm SD $(\mathrm{ng} / \mathrm{mg}$ Cr $)$ & $0.056 \pm 0.231$ & $0.026 \pm 0.053$ & $0.020 \pm 0.034$ & $0.123 \pm 0.387$ & 0.003 \\
\hline Range (ng/mg Cr) & $0.016-2.86$ & $0.016-0.417$ & $0.022-0.223$ & $0.026-2.08$ & \\
\hline
\end{tabular}

$\mathrm{AOH}=$ alternariol; $\mathrm{AME}=$ alternariol monomethyl ether; $\mathrm{TeA}=$ tenuazonic acid; TEN $=$ tentoxin; $\mathrm{Cr}=$ creatinine. ${ }^{\text {a }} p$-values obtained using the Kruskal-Wallis test.

The urinary AOH levels in the present work were higher than the results reported in Portugal (frequency 13\%, range 0.4-9.91 ng/mL) [26], in Belgium, the Czech Republic, France, the Netherlands and Norway (frequency $7.4 \%$, range $0.025-1.57 \mathrm{ng} / \mathrm{mL}$ ) [17] and in Nigeria (frequency 6.7\%, mean $0.06 \mathrm{ng} / \mathrm{mL}$ ) [29]; the urinary AME levels were 
lower than that found in Belgium, the Czech Republic, France, the Netherlands and Norway (frequency $7.4 \%$, range $0.134-22.4 \mathrm{ng} / \mathrm{mL}$ ) [17]; the urinary TeA levels were lower than the values determined in volunteers from Germany (frequency $97.9-100 \%$, mean 6.58-6.8 ng/mL) [24,25], but higher than those from Belgium, the Czech Republic, France, the Netherlands and Norway (frequency $20.7 \%$, range $0.154-28.5 \mathrm{ng} / \mathrm{mL}$ ) [17]. The relatively higher concentrations of the major Alternaria toxins in the present work compared to the other reports might be due to the subtropical monsoon climate of warm and humid in the Yangtze River Delta, which are more favorable for mycotoxigenic fungi growth and subsequent mycotoxin production [30]. Thus, concerns for Alternaria mycotoxins exposure should be raised, according to the present biomonitoring data.

\subsection{Demographic Variables and Urinary Alternaria Mycotoxin Levels}

Distributions of exposure levels for most Alternaria mycotoxins were found by KruskalWallis test to be significantly different between regions (Table 2). The detection frequencies and concentrations of $\mathrm{AOH}$ and TEN in Hangzhou were apparently higher than that of the other two regions, whereas Shanghai showed higher levels of TeA than Nanjing and Hangzhou. The significant difference may be due to a wide range of factors. Climatic characteristics, environmental and storage conditions could influence the fungi growth and mycotoxin production on food products. Different sampling periods and inter-individual variabilities in absorption, metabolism and excretion might affect the urinary Alternaria mycotoxin levels. Moreover, as shown in Table S1, the participants from three cities have different dietary habits. However, no statistically significant correlation between urinary Alternaria mycotoxin concentrations and food consumption $(p<0.05)$ was found with various food types (Table S2), which might be caused by the heterogeneous distributions of mycotoxins in foodstuffs, various routes of mycotoxin exposures, and the inaccurate dietary intakes in questionnaires [31]. Thus, further research is needed to determine if specific regional foods are vectors for Alternaria mycotoxin exposure.

The comparison of urinary Alternaria mycotoxin concentrations among different demographic groups (gender, age and body mass index (BMI)) was depicted in Figure 1. Females presented significantly lower urinary AME concentrations than males $(p<0.01)$, while the urinary TEN concentrations in females were higher than those in males $(p<0.05)$. With regard to age and BMI, no significant difference in all Alternaria mycotoxin concentrations was found, which was in agreement with the monitoring results of urinary Alternaria mycotoxins (AOH, AME and TeA) conducted in European countries [17]. Nevertheless, a number of previous studies described significant demography-related differences in urinary mycotoxin concentrations [31-34]. Besides the mutability of mycotoxin levels in food, these inconclusive findings might also be attributed to dietary characteristics, body fitness, toxicokinetics and toxicodynamics of the target population. Considering the small number of samples in the present study, further research should be conducted to verify the relationships between urinary Alternaria mycotoxin concentrations and demographic factors. 

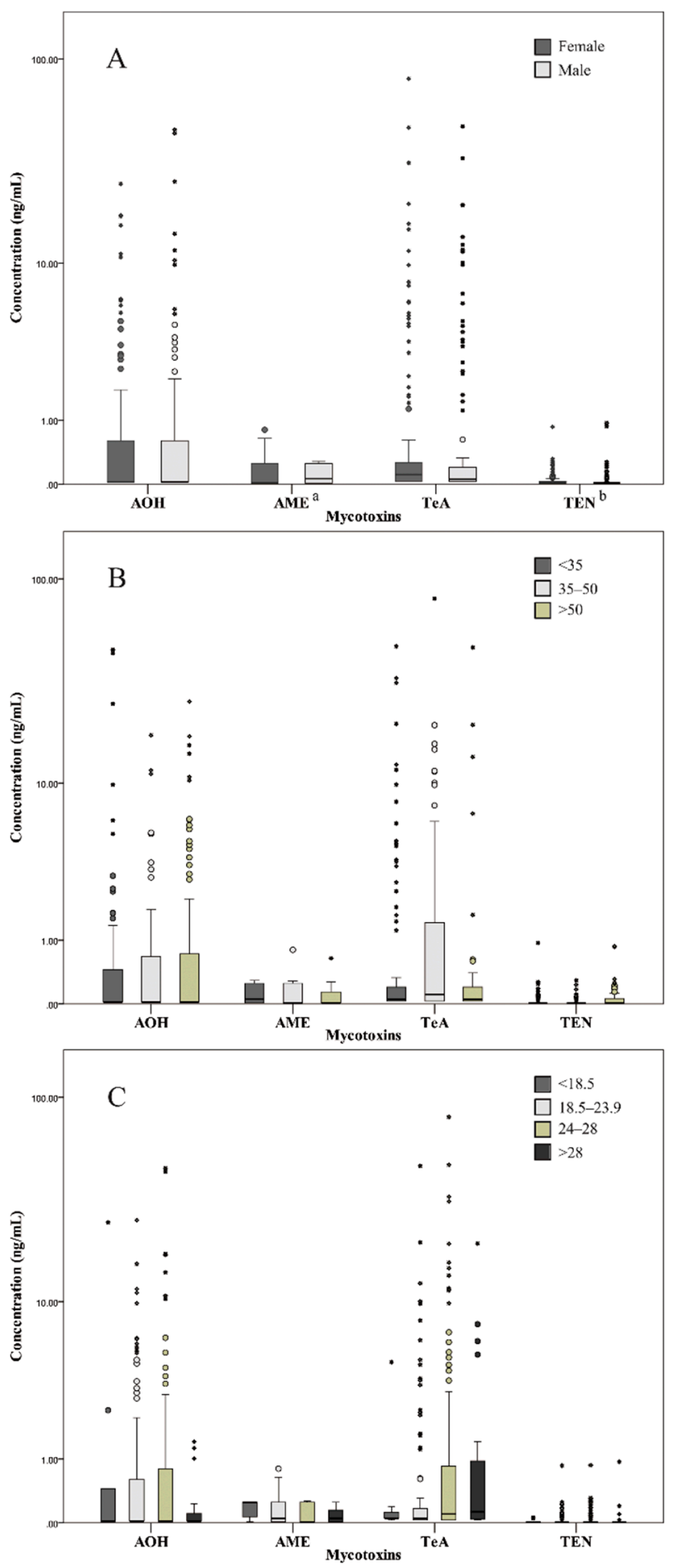

Figure 1. Comparison of Alternaria mycotoxin concentrations detected in urine samples, according to (A) gender, (B) age and (C) BMI. The middle lines in the boxes indicate the median; upper and lower box edges indicate the values of the 25 th and 75 th percentiles. The circles and asterisks correspond to outliers and extremes, respectively. ${ }^{\mathrm{a}}$ : $p$-value $<0.01 ;{ }^{\mathrm{b}}: 0.01<p$-value $<0.05$ by the Mann-Whitney $\mathrm{U}$ test. $\mathrm{AOH}=$ alternariol; $\mathrm{AME}=$ alternariol monomethyl ether; $\mathrm{Te} \mathrm{A}=$ tenuazonic acid; TEN = tentoxin.

\subsection{Probable Daily Intake and Risk Characterization}

As a kind of "emerging mycotoxins", there are limited toxicological data on Alternaria mycotoxins, and the health-based guidance values (HBGV) were absent yet. Thus, EFSA chose to apply the TTC approach for an initial evaluation for dietary exposure of humans to 
Alternaria mycotoxins $[4,35]$. In the present study, the PDI values of Alternaria mycotoxins were estimated based on the urinary concentrations and compared with respective TTC values to evaluate the health risks. However, it is noticeable a lack of information on toxicokinetics of Alternaria mycotoxins. Until now, data on excretion rate derived from human intervention study is only available for TeA. Two volunteers ingested $30 \mu \mathrm{g}$ TeA by the consumption of naturally contaminated food, and the urinary excretion were determined as 87-93\% (mean 89\%) after $24 \mathrm{~h}$ [24]. For other Alternaria mycotoxins, available data were derived from recent studies performed in rats [36,37]. As a consequence, the risk assessment for Alternaria mycotoxins in the present study might be considered a rough estimate.

$\mathrm{AOH}$ and AME were assigned to the class of potential DNA-reactive substances with a TTC value of $2.5 \mathrm{ng} / \mathrm{kg}$ bw/day by EFSA. In the present work, the PDI values for $\mathrm{AOH}$ and AME were calculated to be in the range of 3.28-33,700 ng/ $\mathrm{kg}$ bw/day and 2.33-873 ng/kg bw/day, respectively (Table 3). Similarly, Martins et al. [26] reported the median and maximum values of estimated PDI for AOH in Portugal were 74 and 2451 $\mathrm{ng} / \mathrm{kg}$ bw/day. These results were in line with the assessment performed by EFSA, which confirmed that the TTC values for AOH and AME were frequently exceeded, indicating that additional toxicity data and further research are required to assess the potential health risks $[5,38]$. However, it should be noted that the related health risks might be overestimated in the present study for two reasons. First, the PDI values for $\mathrm{AOH}$ and AME calculated based on respective LOD/2 values were close to or even higher than the PDI values. Therefore, analytical methods with higher sensitivity were required to more accurately estimate the dietary intake of Alternaria mycotoxins. Secondly, the excretion rates derived from rats are low $(<9 \%)$ and a possible increase of this percentage for humans will decrease the PDIs. Therefore, human excretion rates, based on the excreted amount in $24 \mathrm{~h}$ and the calculated dietary intake per day, are required.

Table 3. Estimate of probable daily intakes of Alternaria mycotoxins based on urinary concentrations.

\begin{tabular}{|c|c|c|c|c|c|c|c|c|c|}
\hline \multirow{2}{*}{ Mycotoxins } & \multicolumn{2}{|c|}{ Excretion Rate } & \multicolumn{5}{|c|}{ PDI (ng/kg bw/day) } & \multirow{2}{*}{$\begin{array}{c}\text { TTC } \\
\text { (ng/kg bw/day) }\end{array}$} & \multirow{2}{*}{$\begin{array}{l}\text { Exceeding } \\
\text { TTC }(\%)\end{array}$} \\
\hline & ER (\%) & Reference & Min & Mean & Median & P95 & Max & & \\
\hline \multirow{2}{*}{$\mathrm{AOH}$} & 8.3 & Puntscher et al. [36] ${ }^{a}$ & 3.28 & 419 & 6.57 & 1880 & 11,400 & \multirow[b]{2}{*}{2.5} & 100 \\
\hline & 2.8 & Puntscher et al. [37] a & 9.74 & 1240 & 19.5 & 5580 & 33,700 & & 100 \\
\hline \multirow{2}{*}{ AME } & 6.7 & Puntscher et al. $[36]^{a}$ & 2.33 & 36.8 & 4.76 & 105 & 339 & \multirow{2}{*}{2.5} & 99.2 \\
\hline & 2.6 & Puntscher et al. [37] a & 6.01 & 94.8 & 12.3 & 272 & 873 & & 100 \\
\hline $\mathrm{TeA}$ & 89 & Asam et al. [24] b & 0.468 & 52.1 & 1.75 & 284 & 1940 & 1500 & 0.372 \\
\hline TEN & 0.9 & Puntscher et al. [37] ${ }^{a}$ & 15.2 & 107 & 27.8 & 442 & 2760 & 1500 & 1.12 \\
\hline
\end{tabular}

$\mathrm{AOH}=$ alternariol; $\mathrm{AME}=$ alternariol monomethyl ether; $\mathrm{TeA}=$ tenuazonic acid; $\mathrm{TEN}=$ tentoxin; $\mathrm{ER}=$ excretion rate; $\mathrm{nPDI}=$ probable

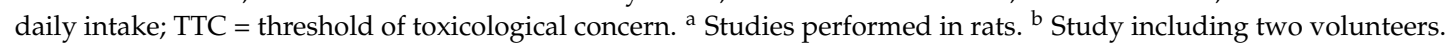

Regarding TeA and TEN, the PDI values estimated were in the range of $0.468-1940 \mathrm{ng} / \mathrm{kg}$ bw/day and $15.2-2760 \mathrm{ng} / \mathrm{kg}$ bw / day, respectively. Only $0.372 \%$ and $1.12 \%$ of the population exhibited PDI exceeding the assumed TDI value of $1500 \mathrm{ng} / \mathrm{kg}$ bw/day, respectively. Similar results were reported in Germany where the PDI values for TeA were 24-1528 ng/ kg bw/day (mean $208 \mathrm{ng} / \mathrm{kg}$ bw/day) and only for one individual the PDI exceeded the TTC value [25]. These results suggest a low risk to the investigated populations in terms of exposure to TeA and TEN.

\section{Conclusions}

In conclusion, a biomonitoring study was performed to evaluate the health risks related to the contamination of major Alternaria mycotoxins in the Yangtze River Delta, China, for the first time. Results indicated a frequent exposure of the investigated Chinese population to four Alternaria mycotoxins (AOH, AME, TeA and TEN). The calculated PDI values of selected Alternaria mycotoxins were even greater than the TTC values and might represent a potential health concern. Nevertheless, these results should be interpreted carefully due to the uncertainties associated with exposure assessments, especially the excretion rates that were used were derived from only two human individuals (TeA) or 
rats $(\mathrm{AOH}, \mathrm{AME}$ and TEN). Another limitation of this study was the collection of first morning urine samples instead of $24 \mathrm{~h}$ urine sample, which should be more appropriate and accurate for exposure assessment. However, the collection of complete $24 \mathrm{~h}$ urine sample in large population was not convenient, time-consuming, and frequently improper or incomplete [12,39]. As an alternative, first morning urine sample was utilized since it could also provide useful information regarding exposure at the population level as indicated by the previous studies [40-43]. Moreover, considering the limited number of samples and the lack of Alternaria mycotoxins concentrations of adolescents and children, the present work could not represent the entire population in the Yangtze River Delta, China. Therefore, the present work was considered as a pilot survey. Further studies with a larger sample size should be conducted to provide better insights regarding the exposure to Alternaria mycotoxins among the general Chinese population.

\section{Materials and Methods}

\subsection{Reagents and Chemicals}

Methanol and acetonitrile were of HPLC grade (Merck Chemicals, Darmstadt, Germany). Ethyl acetate, sodium acetate and ammonium acetate were obtained from Sigma Aldrich (St. Louis, MO, USA). Water was purified on a Milli-Q Plus apparatus (Millipore, Billerica, MA, USA) prior to use. Enzyme $\beta$-glucuronidase/arylsulfatase ( $\beta$-Gluc/ArylS) from Helix pomatia was purchased from Roche (Mannheim, Germany). The standards of $\mathrm{AOH}, \mathrm{AME}, \mathrm{ALT}, \mathrm{TeA}, \mathrm{TEN}$ were purchased from Romer Labs (Union, MO, USA).

\subsection{Study Populations and Sample Collection}

Urine samples were obtained from 269 healthy volunteers (122 females and 147 males) residing in three important cities (Shanghai, Nanjing or Hangzhou) of the Yangtze River Delta, China, between July and November 2019. All participants provided a written consent in accordance with the Helsinki Declaration on ethical principles for medical research involving human subjects, and the study was approved by the local medical ethics committee. During sample collection, the participants were asked to complete a detailed questionnaire with anthropometric information (age, gender, height, and weight), health, occupation and lifestyle factors. Individuals with previous medical records indicating liver, kidney or other metabolic problems were excluded. A food questionnaire on dietary intake in the previous day was administered, in which, typical foods consumed by Chinese people were clearly listed: wheat, maize, rice, vegetables and fruit, meat, nuts and seeds, milk and dairy products, and beverages. The results for the dietary intake of participants are shown in Table S3. The basic demographic characteristics of the study participants are presented in Table S4. The mean age of all participants was $45.4 \pm 17.5$ years (range 18 to 76 years), and the average BMI of the population was $23.3 \pm 3.2 \mathrm{~kg} / \mathrm{m}^{2}$ (range 16.6-32.9 kg/m²). All participants were healthy with no chronic diseases.

The first morning urine sample $(\sim 10 \mathrm{~mL})$ was collected from each participant using $50 \mathrm{~mL}$ sterile centrifuge tubes (Corning, NY, USA). All urine samples were transported to the laboratory in chilled conditions after collection and stored in a freezer $\left(-20^{\circ} \mathrm{C}\right)$ until extraction.

\subsection{Sample Preparation}

Enzymatic cleavage and extraction of Alternaria mycotoxins in urine were performed according to the previous study [27] with minor modifications. Urine samples were thawed at room temperature for $30 \mathrm{~min}$ and vortexed for $2 \mathrm{~min}$. Then, $1 \mathrm{~mL}$ of each sample was digested with $10 \mu \mathrm{L} \beta$-Gluc/ArylS and $1 \mathrm{~mL} 0.2 \mathrm{~mol} / \mathrm{L}$ sodium acetate buffer (PH 5.2-5.3) in water bath at $37^{\circ} \mathrm{C}$ overnight. The digested sample was adjusted to about $\mathrm{pH} 3$ with $\mathrm{HCl}$, and then mixed with $5 \mathrm{~mL}$ of ethyl acetate and vortexed for $2 \mathrm{~min}$. After centrifugation at 12,000 rpm for $5 \mathrm{~min}, 2.5 \mathrm{~mL}$ of the upper organic phase was transferred into a $10 \mathrm{~mL}$ centrifuge tube (Axygen Scientific Inc., Union City, CA, USA), and dried under a stream of nitrogen at $40{ }^{\circ} \mathrm{C}$. The residues were re-dissolved into $250 \mu \mathrm{L}$ of methanol/water containing 
$5 \mathrm{mmol} / \mathrm{L}$ ammonium acetate $(20 / 80, v / v)$ and passed through PTFE membrane syringe filters $(0.22 \mu \mathrm{m})$ before UPLC-MS/MS analysis.

\subsection{UPLC-MS/MS Analysis}

UPLC-MS/MS analysis was conducted on a Waters Acquity UPLC system (Waters, Milford, MA, USA) and an AB SCIEX QTRA ${ }^{\circledR} 5500$ tandem mass spectrometer (AB SCIEX instruments, Foster City, Canada). Separation was achieved on a Waters XBridge ${ }^{\circledR}$ BEH C18 Column $(3.0 \mathrm{~mm} \times 100 \mathrm{~mm}, 2.5 \mu \mathrm{m})$ with the mobile phase consisting of methanol $(\mathrm{A})$ and water containing $5 \mathrm{mmol} / \mathrm{L}$ ammonium acetate (B). A linear gradient elution program was designed as follows: initial 10\% (A), $1 \mathrm{~min} \mathrm{10 \%} \mathrm{(A),} 5 \mathrm{~min} 90 \%$ (A), $6 \mathrm{~min}$ 10\% (A), $7 \mathrm{~min} \mathrm{10 \%} \mathrm{(A)} \mathrm{and} \mathrm{hold} \mathrm{on} \mathrm{for} \mathrm{a} \mathrm{further} 2 \mathrm{~min}$ for re-equilibration, yielding a total run time of $9 \mathrm{~min}$. The flow rate was $0.4 \mathrm{~mL} / \mathrm{min}$, and the injection volume was $3 \mu \mathrm{L}$. The column temperature and sample temperature were maintained at $40{ }^{\circ} \mathrm{C}$ and $5{ }^{\circ} \mathrm{C}$, respectively. Alternaria mycotoxins were analyzed by MS/MS with the electrospray ionization source operated in both positive $\left(\mathrm{ESI}^{+}\right)$and negative $\left(\mathrm{ESI}^{-}\right)$modes. The parameters were set as follows: ion spray voltage, $5.5 \mathrm{kV}$ (positive ion mode) and $4.5 \mathrm{kV}$ (negative ion mode); source temperature, $500{ }^{\circ} \mathrm{C}$; declustering potential, $96 \mathrm{~V}$; entrance potential, $8 \mathrm{~V}$; exit potential, $12 \mathrm{~V}$; curtain gas, 35 psi; ion source gas 1, 50 psi; ion source gas 2, 50 psi; collision gas, 8 psi. Multiple reaction monitoring (MRM) acquisition mode was applied for the determination of the targeted analytes. The parameters and collision energies of precursor and product ions are listed in Table S5. MRM peak integrations and data analysis were carried out using the MultiQuant algorithm from MultiQuant 3.0.2 (AB SCIEX, Foster City, CA, USA).

\subsection{Method Validation}

The established method was validated by determining the linearity, LOD, LOQ, recovery and precision to ensure its sensitivity, accuracy and repeatability, following Commission Regulation 2006/401/EC [44].

Alternaria mycotoxin standards were spiked into methanol/water containing $5 \mathrm{mmol} / \mathrm{L}$ ammonium acetate $(20 / 80, v / v)$ and into blank urine matrices with a concentration sequence of $0.02,0.05,0.1,0.2,0.5,1,2,5,10,20,50$ and $100 \mathrm{ng} / \mathrm{mL}$. Calibrations curves $(1 / x$ weighted) were created for each analyte by plotting the responses versus the concentrations. The SSE, which was calculated by comparing the slope of the matrix-matched calibration curve with that of the standard calibration curve, was used to assess the matrix effects. The sensitivity was assessed by determining LOD and LOQ, which were designed as the concentrations of the analyte in matrix that could provide a signal-to-noise ratio $(\mathrm{S} / \mathrm{N})$ of $3 / 1$ for the second intense transition and 10/1 for the most intense transition, respectively. The recovery, intra- and inter-day precision tests were all performed in five replicates using blank urine samples spiked with low, intermediate and high concentration levels $(0.05,0.2$ and $2 \mathrm{ng} / \mathrm{mL}$ for AME and TEN; $0.1,0.5$ and $5 \mathrm{ng} / \mathrm{mL}$ for $\mathrm{AOH}$ and $\mathrm{TeA} ; 0.5,2$ and $10 \mathrm{ng} / \mathrm{mL}$ for ALT). Recovery was calculated by comparing the measured concentration using the matrix-matched calibration curves with the spiked (theoretical) concentration of each analyte. Recoveries between $70 \%$ and $120 \%$ were considered acceptable. The relative standard deviations (RSDs) determined in the same day were used for evaluation of the intra-day precision, whereas the values in five consecutive days were used for inter-day precision.

\subsection{Creatinine Analysis}

To account for the variability in urine dilution between individual samples, the urinary concentrations of Alternaria mycotoxins were normalized to $\mathrm{Cr}$, which was determined using an enzymatic reaction on a Roche Hitachi 912 Chemistry Analyzer (Roche Hitachi, Basel, Switzerland). According to the proposal of the World Health Organization (WHO) [45], creatinine levels in the range of values $(30-300 \mathrm{mg} / \mathrm{dL})$ were considered acceptable for biomonitoring. 


\subsection{Estimated Dietary Exposure of Alternaria Mycotoxins}

The PDI of the Alternaria mycotoxin was calculated based on the measured urinary concentration according to equation below [25]:

$$
\operatorname{PDI}(\mathrm{ng} / \mathrm{kg} \bullet \mathrm{bw} / \text { day })=\frac{C \times V \times 100}{W \times E}
$$

C: the concentration of Alternaria mycotoxin in urine (ng/L), $V$ : the mean volume of daily urine excretion (1.5 L/day) [39], W: individual body weight $(\mathrm{kg}), E$ : mean urinary excretion rate of Alternaria mycotoxin (\%).

\subsection{Statistical Analysis}

All the statistical analyses were performed using IBM SPSS Statistics software version 22 (SPSS Inc., Chicago, IL, USA). For statistical analysis, urinary concentrations between LOD and LOQ were replaced with $\mathrm{LOQ} / 2$ and the concentrations below LOD were replaced with LOD/2. Differences of mycotoxin concentrations among subgroups were tested with the non-parametric Mann-Whitney U test or Kruskal-Wallis test, and correlation analysis was conducted using Spearman's rank correlation coefficient (two-tailed). A $p$ value $<0.05$ was considered statistically significant.

Supplementary Materials: The following are available online at https:/ /www.mdpi.com/article/10 .3390/toxins13110762/s1, Figure S1: chemical structures of the Alternaria mycotoxins, Table S1: linear range and correlation coefficient (R2) for the five Alternaria mycotoxins in urine samples, Table S2: correlations ( $\mathrm{r}$ ) between urinary Alternaria mycotoxin levels and food consumptions, Table S3: food consumptions of the participants, Table S4: demographic characteristics of the participants, Table S5: MS/MS parameters for five Alternaria mycotoxins.

Author Contributions: Conceptualization, K.F. and Z.H.; methodology, W.G. and Q.H.; software, J.M.; validation, W.G. and Q.H.; formal analysis, K.F. and Q.H.; investigation, K.F. and W.G.; resources, Q.Y.; data cura-tion, K.F.; writing—original draft preparation, K.F.; writing — review and editing, K.F., D.N. and Z.H.; visualization, J.M.; supervision, Z.H. and. Z.Z.; project administration, Z.H. and. Z.Z.; funding acquisition, Z.H. and. Z.Z. All authors have read and agreed to the published version of the manuscript.

Funding: This research was funded by Shanghai Agriculture Applied Technology Development Program, China (Grant No.X2020-02-08-00-12-F01453) and the Science and Technology Innovation Action Plan Project of Shanghai Municipal Commission of Science and Technology (No. 17391901200).

Institutional Review Board Statement: The study was conducted according to the guidelines of the Declaration of Helsinki and approved by the local medical ethics committee.

Informed Consent Statement: Informed consent was obtained from all subjects involved in the study.

Data Availability Statement: The data presented in this study are available at https://www. mdpi.com/journal/toxins/special_issues/Biomonitoring_Assessment_Mycotoxins, accessed date 25 October 2021.

Conflicts of Interest: The authors declare no conflict of interest.

\section{References}

1. Meena, M.; Gupta, S.K.; Swapnil, P.; Zehra, A.; Dubey, M.K.; Upadhyay, R.S. Alternaria toxins: Potential virulence factors and genes related to pathogenesis. Front. Microbiol. 2017, 8, 1451. [CrossRef] [PubMed]

2. Escrivá, L.; Oueslati, S.; Font, G.; Manyes, L. Alternaria mycotoxins in food and feed: An overview. J. Food Qual. 2017, 1569748. [CrossRef]

3. Qiao, X.; Yin, J.; Yang, Y.; Zhang, J.; Shao, B.; Li, H.; Chen, H. Determination of Alternaria mycotoxins in fresh sweet cherries and cherry-based products: Method validation and occurrence. J. Agric. Food Chem. 2018, 66, 11846-11853. [CrossRef] [PubMed]

4. EFSA Panel on Contaminants in the Food Chain (CONTAM). Scientific Opinion on the risks for animal and public health related to the presence of Alternaria toxins in feed and food. EFSA J. 2011, 9, 2407-2504. [CrossRef]

5. EFSA; Arcella, D.; Eskola, M.; Gomez Ruiz, J.A. Scientific report on the dietary exposure assessment to Alternaria toxins in the European population. EFSA J. 2016, 14, 4654-4686. [CrossRef] 
6. Crudo, F.; Varga, E.; Aichinger, G.; Galaverna, G.; Marko, D.; Dall'Asta, C.; Dellafiora, L. Co-occurrence and combinatory effects of Alternaria mycotoxins and other xenobiotics of food origin: Current scenario and future perspectives. Toxins 2019, 11, 640. [CrossRef]

7. Puntscher, H.; Cobankovic, I.; Marko, D.; Warth, B. Quantitation of free and modified Alternaria mycotoxins in European food products by LC-MS/MS. Food Control. 2019, 102, 157-165. [CrossRef]

8. Xing, L.; Zou, L.; Luo, R.; Wang, Y. Determination of five Alternaria toxins in wolfberry using modified QuEChERS and ultra-high performance liquid chromatography-tandem mass spectrometry. Food Chem. 2020, 311, 125975. [CrossRef]

9. Guo, W.; Fan, K.; Nie, D.; Meng, J.; Huang, Q.; Yang, J.; Shen, Y.; Tangni, E.K.; Zhao, Z.; Wu, Y.; et al. Development of a QuEChERS-based UHPLC-MS/MS method for simultaneous determination of six Alternaria toxins in grapes. Toxins 2019, 11, 87. [CrossRef]

10. Meerpoel, C.; Vidal, A.; Andjelkovic, M.; De Boevre, M.; Tangni, E.K.; Huybrechts, B.; Devreese, M.; Croubels, S.; De Saeger, S. Dietary exposure assessment and risk characterization of citrinin and ochratoxin A in Belgium. Food Chem. Toxicol. 2021, 147, 111914. [CrossRef]

11. Arce-Lopez, B.; Lizarraga, E.; Vettorazzi, A.; Gonzalez-Penas, E. Human biomonitoring of mycotoxins in blood, plasma and serum in recent years: A review. Toxins 2020, 12, 147. [CrossRef] [PubMed]

12. Heyndrickx, E.; Sioen, I.; Bellemans, M.; Maeyer, M.D.; Callebaut, A.; Henauw, S.D.; Saeger, S.D. Assessment of mycotoxin exposure in the Belgian population using biomarkers: Aim, design and methods of the BIOMYCO study. Food Addit. Contam. 2014, 31, 924-931. [CrossRef] [PubMed]

13. Habschied, K.; Kanizai Saric, G.; Krstanovic, V.; Mastanjevic, K. Mycotoxins-biomonitoring and human exposure. Toxins 2021, 13, 113. [CrossRef]

14. Turner, P.C.; Snyder, J.A. Development and limitations of exposure biomarkers to dietary contaminants mycotoxins. Toxins 2021, 13, 314. [CrossRef]

15. Al-Jaal, B.A.; Jaganjac, M.; Barcaru, A.; Horvatovich, P.; Latiff, A. Aflatoxin, fumonisin, ochratoxin, zearalenone and deoxynivalenol biomarkers in human biological fluids: A systematic literature review, 2001-2018. Food Chem. Toxicol. 2019, 129, 211-228. [CrossRef]

16. Fan, K.; Xu, J.; Jiang, K.; Liu, X.; Meng, J.; Di Mavungu, J.D.; Guo, W.; Zhang, Z.; Jing, J.; Li, H.; et al. Determination of multiple mycotoxins in paired plasma and urine samples to assess human exposure in Nanjing, China. Environ. Pollut. 2019, 248, 865-873. [CrossRef]

17. De Ruyck, K.; Huybrechts, I.; Yang, S.; Arcella, D.; Claeys, L.; Abbeddou, S.; De Keyzer, W.; De Vries, J.; Ocke, M.; Ruprich, J.; et al. Mycotoxin exposure assessments in a multi-center European validation study by 24 hour dietary recall and biological fluid sampling. Environ. Int. 2020, 137, 105539. [CrossRef]

18. Franco, L.T.; Petta, T.; Rottinghaus, G.E.; Bordin, K.; Gomes, G.A.; Alvito, P.; Assuncao, R.; Oliveira, C.A.F. Assessment of mycotoxin exposure and risk characterization using occurrence data in foods and urinary biomarkers in Brazil. Food Chem. Toxicol. 2019, 128, 21-34. [CrossRef] [PubMed]

19. Chen, C.; Mitchell, N.J.; Gratz, J.; Houpt, E.R.; Gong, Y.; Egner, P.A.; Groopman, J.D.; Riley, R.T.; Showker, J.L.; Svensen, E.; et al. Exposure to aflatoxin and fumonisin in children at risk for growth impairment in rural Tanzania. Environ. Int. 2018, 115, 29-37. [CrossRef]

20. Scheibenzuber, S.; Dick, F.; Asam, S.; Rychlik, M. Analysis of 13 Alternaria mycotoxins including modified forms in beer. Mycotoxin Res. 2021, 37, 149-159. [CrossRef]

21. Bansal, M.; Saifi, I.J.; Dev, I.; Sonkar, A.K.; Dixit, S.; Singh, S.P.; Ansari, K.M. Occurrence of Alternariol and Alternariolmonomethyl ether in edible oils: Their thermal stability and intake assessment in state of Uttar Pradesh, India. J. Food Sci. 2021, 86, 1124-1131. [CrossRef] [PubMed]

22. Walravens, J.; Mikula, H.; Rychlik, M.; Asam, S.; Devos, T.; Njumbe Ediage, E.; Diana Di Mavungu, J.; Jacxsens, L.; Van Landschoot, A.; Vanhaecke, L.; et al. Validated UPLC-MS/MS methods to quantitatefree and conjugated Alternaria toxins in commercially available tomato products and fruit and vegetable juices in Belgium. J. Agric. Food Chem. 2016, 64, 5101-5109. [CrossRef] [PubMed]

23. Zhao, K.; Shao, B.; Yang, D.; Li, F.; Zhu, J. Natural occurrence of Alternaria Toxins in wheat-based products and their dietary exposure in China. PLoS ONE 2015, 10, e0132019. [CrossRef] [PubMed]

24. Asam, S.; Habler, K.; Rychlik, M. Determination of tenuazonic acid in human urine by means of a stable isotope dilution assay. Anal. Bioanal. Chem. 2013, 405, 4149-4158. [CrossRef]

25. Hovelmann, Y.; Hickert, S.; Cramer, B.; Humpf, H.U. Determination of exposure to the Alternaria mycotoxin tenuazonic acid and its isomer allo-tenuazonic acid in a German population by stable isotope dilution HPLC-MS(3). J. Agric. Food Chem. 2016, 64, 6641-6647. [CrossRef] [PubMed]

26. Martins, C.; Vidal, A.; De Boevre, M.; De Saeger, S.; Nunes, C.; Torres, D.; Goios, A.; Lopes, C.; Assuncao, R.; Alvito, P. Exposure assessment of Portuguese population to multiple mycotoxins: The human biomonitoring approach. Int. J. Hyg. Environ. Health 2019, 222, 913-925. [CrossRef] [PubMed]

27. Qiao, X.; Zhang, J.; Yang, Y.; Yin, J.; Li, H.; Xing, Y.; Shao, B. Development of a simple and rapid LC-MS/MS method for the simultaneous quantification of five Alternaria mycotoxins in human urine. J. Chromatogr. B 2020, 1144, 122096. [CrossRef] 
28. Schmidt, J.; Cramer, B.; Turner, P.C.; Stoltzfus, R.J.; Humphrey, J.H.; Smith, L.E.; Humpf, H.U. Determination of urinary mycotoxin biomarkers using a sensitive online solid phase extraction-UHPLC-MS/MS method. Toxins 2021, 13, 418. [CrossRef]

29. Sarkanj, B.; Ezekiel, C.N.; Turner, P.C.; Abia, W.A.; Rychlik, M.; Krska, R.; Sulyok, M.; Warth, B. Ultra-sensitive, stable isotope assisted quantification of multiple urinary mycotoxin exposure biomarkers. Anal. Chim. Acta. 2018, 1019, 84-92. [CrossRef]

30. Selvaraj, J.N.; Wang, Y.; Zhou, L.; Zhao, Y.; Xing, F.; Dai, X.; Liu, Y. Recent mycotoxin survey data and advanced mycotoxin detection techniques reported from China: A review. Food Addit. Contam. Part. A 2015, 32, 440-452. [CrossRef]

31. Huang, Q.; Jiang, K.; Tang, Z.; Fan, K.; Meng, J.; Nie, D.; Zhao, Z.; Wu, Y.; Han, Z. Exposure assessment of multiple mycotoxins and cumulative health risk assessment: A biomonitoring-based Study in the Yangtze River Delta, China. Toxins 2021, 13, 103. [CrossRef] [PubMed]

32. Ali, N.; Manirujjaman, M.; Rana, S.; Degen, G.H. Determination of aflatoxin M1 and deoxynivalenol biomarkers in infants and children urines from Bangladesh. Arch. Toxicol. 2020, 94, 3775-3786. [CrossRef] [PubMed]

33. Rodriguez-Carrasco, Y.; Izzo, L.; Gaspari, A.; Graziani, G.; Manes, J.; Ritieni, A. Urinary levels of enniatin B and its phase I metabolites: First human pilot biomonitoring study. Food Chem. Toxicol. 2018, 118, 454-459. [CrossRef] [PubMed]

34. Wang, X.; Liang, J.; Cao, P.; Zhou, S.; Wu, A.; Gao, P.; Xu, H.; Liu, Z.; Gong, Y. Biomonitoring study of deoxynivalenol exposure in Chinese inhabitants. Int. J. Environ. Res. Public Health 2019, 16, 2169. [CrossRef] [PubMed]

35. Jank, B.; Rath, J.; Marko, D.; Vejdovszky, K.; Rauscher-Gabernig, E. Exploring the TTC approach as a basis for risk management: The example of emerging Alternaria mycotoxins. Toxicol. Lett. 2020, 320, 124-128. [CrossRef]

36. Puntscher, H.; Hankele, S.; Tillmann, K.; Attakpah, E.; Braun, D.; Kutt, M.L.; Del Favero, G.; Aichinger, G.; Pahlke, G.; Hoger, H.; et al. First insights into Alternaria multi-toxin in vivo metabolism. Toxicol. Lett. 2019, 301, 168-178. [CrossRef]

37. Puntscher, H.; Aichinger, G.; Grabher, S.; Attakpah, E.; Kruger, F.; Tillmann, K.; Motschnig, T.; Hohenbichler, J.; Braun, D.; Plasenzotti, R.; et al. Bioavailability, metabolism, and excretion of a complex Alternaria culture extract versus altertoxin II: A comparative study in rats. Arch. Toxicol. 2019, 93, 3153-3167. [CrossRef]

38. Bruschweiler, B.J. The TTC approach in practice and its impact on risk assessment and risk management in food safety. A regulatory toxicologist's perspective. Chimia 2014, 68, 710-715. [CrossRef] [PubMed]

39. Eriksen, G.S.; Knutsen, H.K.; Sandvik, M.; Brantsæter, A.L. Urinary deoxynivalenol as a biomarker of exposure in different age, life stage and dietary practice population groups. Environ. Int. 2021, 157, 106804. [CrossRef]

40. Heyndrickx, E.; Sioen, I.; Huybrechts, B.; Callebaut, A.; De Henauw, S.; De Saeger, S. Human biomonitoring of multiple mycotoxins in the Belgian population: Results of the BIOMYCO study. Environ. Int. 2015, 84, 82-89. [CrossRef] [PubMed]

41. Zhang, S.; Zhou, S.; Gong, Y.Y.; Zhao, Y.; Wu, Y. Human dietary and internal exposure to zearalenone based on a 24 hour duplicate diet and following morning urine study. Environ. Int. 2020, 142, 105852. [CrossRef] [PubMed]

42. Gratz, S.W.; Currie, V.; Duncan, G.; Jackson, D. Multimycotoxin exposure assessment in UK children using urinary biomarkers-a pilot survey. J. Agric. Food Chem. 2020, 68, 351-357. [CrossRef] [PubMed]

43. Narváez, A.; Izzo, L.; Rodríguez-Carrasco, Y.; Ritieni, A. Citrinin dietary exposure assessment approach through human biomonitoring high-resolution 'mass spectrometry-based data. J. Agric. Food Chem. 2021, 69, 6330-6338. [CrossRef] [PubMed]

44. European Commission. Decision 2006/401/EC Laying down the methods of sampling and analysis for the official control of the levels of mycotoxins in foodstuffs. Off. J. Eur. Commun 2006, L70, 12e34.

45. World Health Organization (WHO). Biological Monitoring of Chemical Exposure in the Workplace; World Health Organization: Geneva, Switzerland, 1996. 